\title{
ENSAYO DE TRES TIPOS DE ALIMENTACIÓN PARA LOMBRICES
}

\author{
Frank Cruz Sisniega *
}

\section{RESUMEN}

El experimento se llevó a cabo entre los meses de abril y agosto de 1995, en las instalaciones del Centro Regional de Investigaciones del IIAP-Madre de Dios, en el km 22,3 de la carretera a Mazuko.

El experimento consistió en evaluar tres tipos de alimentación para lombrices, con la finalidad de aprovechar y determinar los insumos más adecuados para su crianza y producción de humus.

Al respecto, se tuvo como alimento base estiércol de ovino, el cual fue complementado con residuos de cosechas y subproductos de actividades agroindustriales.

Palabras clave: Evaluación de dietas, lombrices, fermentación, mineralización, humus de lombrices.

\begin{abstract}
The experiment was performed between April and August, 1995 in the premises of the Centro Regional de Investigación of IIAP-Madre de Dios at the 22,3 km of the highway to Mazuko.

It consisted on the evaluation of three types of earthworm food with the purpose of taking advantage of and determining the most adequate elements for the caring of earthworms and the production of humus.
\end{abstract}

In this regard, sheep defecatjon which was complemented with residues from harvest and subproducts of agroindustrial activities. 
Key words:

Diet evaluation, earthworm, fermentation, mineralization earthworm humus.

\section{INTRODUCCION}

El cultivo de lombrices se inició y desarrolló en América del Norte y, en vista de h gran utilidad de sus subproductos, la lombricultura se propagó a otras partes de mundo. Las lombrices están dotadas de un extraordinario aparato digestivo, el mis mo que les permite alimentarse de una gran variedad de desechos orgánicos, principalmente de estiércol de animales, restos de legumbres, hortalizas, papel, etc, los cuales deben estar previamente fermentados para su mineralización y conversión en humus, el que constituye el mejor fertilizante orgánico existente, rico en alimentos mayores y menores.

En el Perú, la crianza de lombrices se inició hace algunos años. En la Amazonía, especialmente en el departamento de Ucayali, las experiencias del IJAP son alentadoras, ya que utilizan el humus de lombrices como una alternativa barata para la recuperación de suelos degradados y eliminación de desechos orgánicos.

En el departamento de Madre de Dios, la primera experiencia de crianza de lombrices la inició el Proyecto Especial Madre de Dios; sin embargo, los resultados fueron poco alentadores, principalmente por la falta de planificación en lo que respecta a los insumos alimenticios para las lombrices.

El IIAP-Madre de Dios, en la provincia de Tambopata, inició la primera experiencia en crianza de lombrices con buenos resultados, utilizando residuos de cosechas y estiércol de ovinos, por lo cual consideró la ejecución del ensayo, con la finalidad de obtener información que permita determinar los insumos más recomendables para la producción de humus.

\section{MATERIALES Y METODOS}

El experimento se realizó utilizando tres lechos de crianza de lombrices de $15 \mathrm{~m}^{2}$ cada uno, los cuales fueron inoculados con aproximadamente 20000 lombrices por lecho, equivalente a 1330 lombrices por $\mathrm{m}^{2}$. Las dietas alimenticias fueron:

Estiércol de ovino más residuos vegetales (malezas de hoja anchas y gramíneas).

Estiércol de ovino más aserrín. 
Estiércol de ovino más cáscara de arroz.

En todos los casos, la preparación de las dietas estuvo conformada por $\mathbf{7 0} \%$ de estiércol y $\mathbf{3 0} \%$ del componente residuos vegetales y agroindustriales. La crianza se realizó con la lombriz roja de California Eisenia Joetida. El sistema de crianza fue en cajones de $1 \mathrm{~m}$ de ancho y 15 de largo, y debido a que la zona es lluviosa los lechos de crianza estaban bajo techo. Los riegos fueron diarios e interdiarios, en ocasiones hasta dos veces al día: por la mañana y tarde. Cada 15 días se procedía al aireado de los lechos y desmenuzado de terrones.

\section{RESULTADOS}

a) Referente a la producción de humus por tratamiento se obtuvieron los resultados siguientes:

Dieta 1: Estiércol más residuos vegetales $\quad 1326 \mathrm{~kg}$.

Dieta 2: Estiércol más aserrín $1210 \mathrm{~kg}$.

Dieta 3: Estiércol más cáscara de arroz $\quad 1138 \mathrm{~kg}$.

En todos los casos, la altura máxima de llenado de lechos fue de 0,25 m.

b) Referente a la mineralización del alimento en humus.

Los períodos de mineralización de las dietas en humus fueron:

Dieta 2: Estiércol más aserrín 90 días.

Dieta 3: Estiércol más cáscara de arroz 100 días.

Dieta 1: Estiércol más residuos vegetales 115 días.

c) Referente a la aceptación del alimento por lombrices, las dictas más aceptadas fueron las mezclas estiércol más aserrín y estiércol más residuos vegetales y la menos aceptada estiércol más cáscara de arroz.

d) Referente al manejo de componentes de dietas.

Las dietas más fáciles de trabajar resultaron ser las mezclas estiércol más aserrín y estiércol más cáscara de arroz; la mezcla estiércol más residuos vegetales presentó una mayor dificultad al manejo, lo cual se explica por el grado de desmenuzado que tenían el aserrín y la paja de arroz. 
El tiempo de fermentación de las mezclas estiércol más aserrín y estiércol más cáscara de arroz fue de 35 días, mientras que en la dieta estiércol más residuos vegetales fue de 40 días.

e) Referente al desarrollo de población de lombrices.

La mezcla alimenticia aserrín más estiércol resultó ser el medio más favorable para el desarrollo de las lombrices: se encontró mayor cantidad de lombrices, con tamaño de hasta $10 \mathrm{~cm}$ y pesos de $1 \mathrm{gr}$.

En la mezcla estiércol más residuos vegetales, la proliferación, tamaños y pesos de lombrices fue similar a la anterior, mientras que en la mezcla estiércol más cáscara de arroz la proliferación de lombrices resultó ser similar a las anteriores, aunque la diferencia estuvo en el desarrollo de tamaño y peso, el cual fue menor.

\section{DISCUSION DE RESULTADOS}

- La producción de humus fue mayor en la dieta de residuos vegetales más estiércol; ello se explica por la consistencia de los residuos vegetales, los cuales estaban constituidos por malas hierbas, los que al formar la mezcla dejaban menos espacios; esto no sucedía con el aserrín y la cáscara de arroz, los que actuaban corno esponja y que sin embargo dejaban mayor cantidad de espacios porosos. En todos los casos, la producción de humus puede incrementarse considerablemente, mejorando las condiciones de crianza y llenado de los lechos a una mayor altura.

- Debido al grado de desmenuzamiento del aserrín y la cáscara de arroz que favorecía las condiciones de aireación, humedad y manejo del lecho, la mineralización de los alimentos en humus fue más rápida en las dietas que contenían estos componentes.

- Las mezclas conformadas por estiércol más aserrín y estiércol más residuos vegetales fueron mejor aceptadas por las lombrices debido a su suavidad una vez fermentada, lo que no ocurre con la cáscara de arroz que difícilmente llega a descomponerse en su totalidad; ello se manifiesta en los residuos que se observan en el humus.

La aceptación del alimento tiene incidencia en el desarrollo de las lombrices y reducción del tiempo de mineralización. 


\section{CONCLUSIONES Y RECOMENDACIONES}

1) La mejor dieta resultó ser la mezcla estiércol más aserrín, debido a su menor tiempo de humificación, mayor desarrollo de lombrices en tamaño, peso y población y asimismo por ser de fácil manejo durante la fermentación y humificación, menor frecuencia de riegos y excelente presentación del humus.

2) La mayor producción de humus se obtuvo con la dieta estiércol más residuos vegetales.

3) La dieta menos recomendable resultó ser la mezcla estiércol más cáscara de arroz, por presentar residuos de humus, menor desarrollo de lombrices y menor producción de humus.

4) La opción por una u otra mezcla alimenticia dependerá de la ubicación del criadero de lombrices y su relación con la disponibilidad de insumos. Para el ensayo, la mezcla estiércol más residuos vegetales resulta la más favorable por tener los insumos en el Centro Experimental.

5) Se recomienda ensayar otros insumos en la formulación de dietas para la producción de humus.

\section{B1BLIOGRAFIA}

COMPAGNONI, L. 1995. Cría moderna de las lombrices. Barcelona (España).

RIOS, O; SALAS, 5. y SANCHEZ M. 1993. Manual de lombricultiira en trópico húmedo. Iquitos (Perú). 